\title{
Improving Business Logistics using Barcode Scanners
}

\author{
Niharika Garg \\ Department of Computer Science \\ ITM University \\ Gurgaon, Haryana122001, India
}

\begin{abstract}
One of the latest pieces of technology that you can use to improve logistics is the wireless barcode scanner which is extremely beneficial for a business. These devices by scanning a barcode on a product package which then transmits data back to a host computer depending on how it is set up. So if we have a warehouse and we have products that are being sent out to other locations, then these devices can be used to store that information. This is a much better solution versus having to manually keep track of this data which would be time consuming. Improving business logistics is especially important in this day and age when competition is fierce. If this is the case, then we simply need to use every tool at our disposal so we can cut down on costs and improve processes that bring in more income.
\end{abstract}

\section{Keywords}

Barcode Scanners, Logistics, Handheld Devices, RFID, Pocket PC Applications.

\section{A REVIEW OF THE BARCODE SCANNER}

Computers cannot read bar codes. For a computer to make use of the information contained in the bar code, the bar code data must be captured and decoded into a data format that the computer can process. The device that reads or captures the bar code information and sends it to the decoder is known as the bar code reader, generally called bar code scanner. These scanners are photo sensors that read the barcodes and eventually convert them into readable text that is then displayed and kept on a computer or laptop. Even though it appears to be a very long process but actually it just takes a few milliseconds. Basically, there are three vital components of a barcode reader and they are the scanner, the decoder and lastly the cable. The purpose of the decoder here is to convert the electrical energy into date of numbers and letter then all the data will be forwarded to a PC to be analyzed by software.

These scanners are probably the most widely used devices or tools today and they have with them so many models are being used in different industries which includes manufacturing, warehousing, education, healthcare and lastly in the field service. The high utility aspect and the popularity of the scanners have resulted in the introduction of many varieties.

\section{HOW TO MAKE THE CHOICE OF BARCODE SCANNER}

Businesses nowadays are best handled with the use and help of a barcode scanner. If you are thinking of using only one scanner for your business, you should think twice. As you may know there are different types of barcode scanners for every type of business. Choosing the proper barcode scanner will help you with cost savings and improve efficiency of your business [1].

With all the choices available, it is important to understand your environment and application very well before making decisions. The following factors can be considered while making decisions:

2.1 What type of environment will the bar code scanner be used in? Harsh, as in factory or normal as in a store. 2.2 Is continuous or periodic scanning needed? 2.3 Is hands-free or hand-held capability required? 2.4 Will scanning be conducted close to the bar code or from a distance?

2.5 What will the bar code scanner connect to? 2.6 Will the information scanned be needed in real time?

\section{TYPES OF BARCODE SCANNERS}

The varieties of these scanners can very well be distinguished by their form factor as well as their scanning technologies. The main difference in form factors is the amount of operator manipulation required. The scanning technology should be chosen based on the application and requirements. Based on these factors, the following are the categories:

\section{Scanner by Technology}

a. Pen Type Readers or Bar Code wands

b. CCD (Charge Couple Devices) Scanning - Scan very close to barcode

c. Laser Scanning - No need to bring barcode very close

d. Image Scanning - Capture image and then read barcode [5].

e. RFID scanning - Works on Radio and detect active/passive tags

f. Object Recognition - recognize shapes

Scanner by Application

a. Fixed Scanner - Connected by USB. Need to scan each barcode by hand

b. Hands-Free or Fixed Mount Barcode Scanners Fixed on table. Just put the item in front to scan

c. Bluetooth Scanner - Connected with PC through Bluetooth

d. Portable Scanners - Works offline and have their own memory. We can take it anywhere to scan and then later synch data with PC through cradle.

e. Wireless scanner - Connected to PC/Server through the wireless network

\subsection{Scanners by technology}

Scanning technology is constantly evolving and providing industries with more choices in data capture solutions. Deciding which scanning technology is right for your application can be a difficult task. Knowing the advantages and applications in which these two technologies are used is the first step to success. The key to deciding between these two technologies is determining which fits the requirements and budget of your business most accurately. 


\subsubsection{Pen Type Readers or Bar Code wands}

Pen type barcode readers have a light source and a photo diode placed next to each other in the tip of a pen or wand. To read a bar code, you drag the tip of the pen across all the bars, in a steady even motion. The photo diode measures the intensity of the light reflected back from the light source and generates a waveform corresponding to the widths of the bars and spaces in the bar code. The barcode reader sends the waveform to the decoder, which decodes the waveform and sends it to the computer in a traditional data format.

Table 1. Features of Pen Type Readers

\begin{tabular}{|c|c|}
\hline Advantages & Disadvantages \\
\hline $\begin{array}{c}\text { Simple to } \\
\text { operate }\end{array}$ & $\begin{array}{c}\text { The wand must come into } \\
\text { contact with the bar code, } \\
\text { which can present a } \\
\text { challenge. }\end{array}$ \\
\hline Least expensive & $\begin{array}{c}\text { A bar code may become } \\
\text { smeared or damaged }\end{array}$ \\
\hline $\begin{array}{c}\text { Durable and } \\
\text { contains no } \\
\text { moving parts }\end{array}$ & $\begin{array}{c}\text { A wand is "human powered," } \\
\text { which means that it must be } \\
\text { held at the proper angle and } \\
\text { moved at the proper speed }\end{array}$ \\
\cline { 1 - 2 } $\begin{array}{c}\text { Light in weight } \\
\text { and easy to } \\
\text { hold like a pen }\end{array}$ & \multicolumn{2}{|c}{} \\
\hline
\end{tabular}

\subsubsection{Laser}

Barcode

Scanners

Laser barcode scanners work the same way as pen type barcode readers. The only main difference is that Laser barcode scanners use a laser beam as their light source, and typically employ either a reciprocating mirror or a rotating prism to scan the laser beam back and forth across the bar code. As with the pen type bar code reader, a photo diode is used to measure the intensity of the light reflected back from the bar code.

Table 2. Features of Laser Scanners

\begin{tabular}{|c|c|}
\hline Advantages & Disadvantages \\
\hline $\begin{array}{c}\text { Reading labels } \\
\text { accurately, from larger } \\
\text { distance, and could read } \\
\text { wider labels as well }\end{array}$ & \multirow{7}{*}{$\begin{array}{l}\text { Have movable } \\
\text { parts, which } \\
\text { makes them less } \\
\text { durable }\end{array}$} \\
\hline Easier to use and handle & \\
\hline $\begin{array}{l}\text { Capability to read up to } \\
500 \text { labels per second }\end{array}$ & \\
\hline $\begin{array}{l}\text { Great feature, called } \\
\text { motion tolerance. This } \\
\text { allows the operator to } \\
\text { "sweep" a few labels, } \\
\text { without having to press } \\
\text { and release the trigger for } \\
\text { every label. }\end{array}$ & \\
\hline $\begin{array}{c}\text { Read wrinkled and } \\
\text { broken barcodes as well }\end{array}$ & \\
\hline $\begin{array}{l}\text { Can read barcodes even } \\
\text { when the barcode or } \\
\text { scanner is in motion, } \\
\text { quickly and accurately, } \\
\text { allowing for fast decodes }\end{array}$ & \\
\hline Ideal for long distance & \\
\hline
\end{tabular}

\begin{tabular}{|c|c|}
\hline scanning & \\
\hline $\begin{array}{c}\text { Decoding UPC/EAN and } \\
\text { other 1D barcodes used } \\
\text { in retail }\end{array}$ & \\
\hline Self-Service shopping & $\begin{array}{l}\text { More expensive } \\
\text { than the CCD } \\
\text { scanners }\end{array}$ \\
\hline
\end{tabular}

\subsubsection{CCD Barcode Scanners}

CCD barcode scanners use an array of tiny light sensors lined up in a row in the head of the barcode reader. Voltage waveform corresponding to the bars and spaces of the bar code is generated and sent to the decoder, which decodes the data and sends it to the computer. The main difference between a CCD barcode scanner, a pen type barcode scanner, and laser barcode scanner is that the CCD barcode scanner measures emitted ambient light from the bar code whereas pen or laser barcode scanners measure reflected light of a specific frequency originating from the scanner itself.

Table 3. Features of CCD Scanners

\begin{tabular}{|c|c|}
\hline Advantages & Disadvantages \\
\hline $\begin{array}{l}\text { CCD scanners } \\
\text { incorporate use of LED } \\
\text { lights for illuminating } \\
\text { the barcode. They last } \\
\text { for about ten times } \\
\text { longer than laser } \\
\text { scanners. }\end{array}$ & $\begin{array}{c}\text { Its reading } \\
\text { performance reduced } \\
\text { under strong } \\
\text { illuminating } \\
\text { environments such as } \\
\text { outdoors usages }\end{array}$ \\
\hline $\begin{array}{l}\text { CCD scanners do not } \\
\text { have any moving parts. } \\
\text { So, they are less } \\
\text { susceptible to damage } \\
\text { or failure. They are } \\
\text { resistant to regular wear } \\
\text { and tear. }\end{array}$ & $\begin{array}{l}\text { Scan distance or so } \\
\text { called "scan depth of } \\
\text { field". }\end{array}$ \\
\hline $\begin{array}{l}\text { Do not use any laser } \\
\text { beams, they are not } \\
\text { associated with any } \\
\text { safety specifications. }\end{array}$ & $\begin{array}{c}\text { Can only read } \\
\text { barcodes of three or } \\
\text { four inches in length } \\
\text { or smaller. }\end{array}$ \\
\hline $\begin{array}{l}\text { Higher scanning rate } \\
\text { than that of laser } \\
\text { scanners. }\end{array}$ & \multirow{4}{*}{$\begin{array}{l}\text { Has a limited width, } \\
\text { and will not read bar } \\
\text { codes that are wider } \\
\text { than the face of the } \\
\text { scanner. }\end{array}$} \\
\hline Inexpensive & \\
\hline $\begin{array}{l}\text { To read bar codes } \\
\text { quickly and easily. }\end{array}$ & \\
\hline $\begin{array}{l}\text { Popular for use in point } \\
\text { of sale applications. }\end{array}$ & \\
\hline
\end{tabular}

\subsubsection{Camera Based Barcode Readers[5]}

The camera based barcode readers use a small video camera to capture an image of a bar code. The barcode reader then uses sophisticated digital image processing techniques to decode the bar code [2]. 
Table 4. Features of Camera Based Scanner

\begin{tabular}{|c|c|}
\hline Advantages & Disadvantages \\
\hline $\begin{array}{c}\text { Works similar to digital } \\
\text { camera, but much faster }\end{array}$ & $\begin{array}{c}\text { Distortion, } \\
\text { reflections, } \\
\text { shadows, low } \\
\text { contrast }\end{array}$ \\
\hline $\begin{array}{c}\text { It can read both 1D and 2D } \\
\text { barcodes }\end{array}$ & \\
\hline $\begin{array}{c}\text { Provide omni-directional } \\
\text { scanning so that barcodes } \\
\text { can be read easily from any } \\
\text { orientation. }\end{array}$ & \\
\hline $\begin{array}{c}\text { Capture images such as a } \\
\text { signature or even } \\
\text { photograph a damaged box. }\end{array}$ & \\
\hline $\begin{array}{c}\text { Decoding DPM (Direct Part } \\
\text { Marking) }\end{array}$ & \\
\hline
\end{tabular}

\subsubsection{RFID}

Bar coding is a mature technology that has been around for many years, as opposed to RFID, which is still in its infancy. Additionally, the components used to read and write barcodes have decreased in cost because of this maturity and sales volume. There are many additional issues to consider with RFID. However, overall, RFID has many advantages over bar coding. In some cases, these advantages outweigh the disadvantages and high cost of the components. Decision makers must carefully consider whether RFID really provides an advantage over bar coding in their business model $[3,4]$.

Table 5. Features of RFID

\begin{tabular}{|c|c|}
\hline Advantages & Disadvantages \\
\hline $\begin{array}{l}\text { No Special Positioning } \\
\text { Needed-because RFID tags can } \\
\text { be read in any orientation and } \\
\text { even hidden tags can be } \\
\text { scanned as long as the radio } \\
\text { frequency is still at its range or } \\
\text { shorter }\end{array}$ & Expensive \\
\hline $\begin{array}{l}\text { RFID needs no lens to clean } \\
\text { and line-up }\end{array}$ & $\begin{array}{l}\text { Vulnerable to } \\
\text { damage - Water, } \\
\text { static discharge or } \\
\text { high-powered } \\
\text { magnetic surges } \\
\text { (such as lightning } \\
\text { strike) may } \\
\text { damage the tags. }\end{array}$ \\
\hline $\begin{array}{l}\text { Can be embedded in the } \\
\text { product during manufacture } \\
\text { unlike barcodes }\end{array}$ & Security \\
\hline $\begin{array}{l}\text { Does not need to be very near } \\
\text { with the tag to be scanned. }\end{array}$ & $\begin{array}{l}\text { Dead areas and } \\
\text { orientation } \\
\text { problems- certain } \\
\text { areas that have } \\
\text { weaker signals or } \\
\text { interference. }\end{array}$ \\
\hline Easy to Install & $\begin{array}{l}\text { Ghost tags - In rare } \\
\text { cases, if multiple } \\
\text { tags are read at the }\end{array}$ \\
\hline
\end{tabular}

\begin{tabular}{|c|c|}
\hline & $\begin{array}{l}\text { same time the } \\
\text { reader will } \\
\text { sometimes read a } \\
\text { tag that does not } \\
\text { exist. }\end{array}$ \\
\hline Can Identify Moving Objects & $\begin{array}{l}\text { Proximity issues - } \\
\text { RFID tags cannot } \\
\text { be read well when } \\
\text { placed on metal or } \\
\text { liquid objects or } \\
\text { when these objects } \\
\text { are between the } \\
\text { reader and the tag. }\end{array}$ \\
\hline $\begin{array}{c}\text { Not only performs reading but } \\
\text { writing also-RFID Read and } \\
\text { Write Tags }\end{array}$ & \multirow{4}{*}{$\begin{array}{l}\text { Unread tags - } \\
\text { When reading } \\
\text { multiple tags at the } \\
\text { same time }\end{array}$} \\
\hline $\begin{array}{l}\text { Several items can be scanned at } \\
\text { the same time }\end{array}$ & \\
\hline $\begin{array}{l}\text { Return on Investment (ROI)- } \\
\text { costly but more efficient and } \\
\text { accurate }\end{array}$ & \\
\hline Less Vulnerable to Damage & \\
\hline
\end{tabular}

\subsubsection{Object Recognition Scanners}

Some of the features of the ORS (Object Recognition Scanners) are:

a. Recognizes items in a supermarket without the use of a bar code.

b. Ability to discern between different types of fruits and vegetables.

c. The noise is eliminated from the beginning, so the scanner can recognize objects very fast, even while they're moving.

d. The scanner will also be able to recognize items such as fresh fruits and vegetables, beverage cans and coupons, packaged items like bread and canned goods

e. No experience required. Easy to learn

f. Scanner uses a camera to recognize items rather than depending on barcodes and keyed-in codes. The camera is connected to a system that stores information about all of the products the store sells. g. The system also recognizes pre-packaged items just like a standard scanner. It would come preloaded with a database of fresh produce and other items to make the system easier to integrate into an existing store.

h. It works similarly to facial recognition technology, but for food instead of humans.

\subsection{Scanners by application}

\subsubsection{Fixed Scanners (USB Barcode scanners)}

The USB barcode scanner offers more flexibility for the user in order to reach certain locations that are not that easy to access. This type of scanner can easily be defined just by its name and there is no other reason to carry around a connecting device to feed all the necessary information to as it is just built right into the technology. 


\subsubsection{Hands-Free or Fixed Mount Barcode} Scanners

Fixed mount barcode scanners and 2D imagers allow for hands-free or high-speed automated barcode scanning. These have many applications, including sorting systems, point-ofsale, work-in-process and healthcare. This type of scanner is anchored so that the user can scan bar codes using both hands. Versatile, durable, and extremely reliable, high-throughput scanners, boost productivity to greater levels with minimal employee effort. This scanner is best used for high volume general retail, liquor stores, and convenience stores.

\subsubsection{Portable scanners}

This is a handheld battery operated bar code reader that stores the data in memory for later uploading. In addition to a bar code scanner, a portable bar code reader has an LCD display and a keyboard. The user can walk around, scanning and keying in data and getting a response from the computer with each entry. Portable Palm Terminals combine palm computing with integrated bar code laser scanning.

\subsubsection{Wireless scanner}

This scanner is for factory or warehouse applications where the cable/cord restricts movement. In a harsh environment where the cable can get damaged and make your scanner system inoperable, cordless scanner is the best solution. In shipping and receiving applications where the cable denies access, cordless scanner is the answer. In retail applications where a cabled scanner limits access beyond the counter area, cordless scanner is the solution. Cordless scanner is ideal for scanning heavy, oversized or bulk items that are difficult to place on the counter at checkout. With the wireless barcode scanner, it greatly gives the operator the entire freedom to roam around a certain location they are in while still staying connected to your network via the new Bluetooth barcode scanner or technology.

\subsubsection{Bluetooth Barcode scanners}

It looks and functions the same as the normal cordless scanners does. The only difference between the two is how the information is being transmitted.

\section{COMPARING THE SCANNERS}

Table 6. Comparing the scanners

\begin{tabular}{|c|c|c|c|c|c|c|}
\hline $\begin{array}{c}\text { Scanner by } \\
\text { Application/Sca } \\
\text { nner by } \\
\text { Technology }\end{array}$ & Pen Type & CCD & Laser Scanning & Image Scanning & RFID scanning & $\begin{array}{c}\text { Object } \\
\text { Recognition }\end{array}$ \\
\hline Fixed Scanner & Y & Y & Y & Y & Y & Y \\
\hline Hands-Free & N & Y & Y & N & Y & Y \\
\hline $\begin{array}{c}\text { Bluetooth } \\
\text { Scanner }\end{array}$ & N & N & Y & Y & Y & Y \\
\hline $\begin{array}{c}\text { Portable } \\
\text { Scanners }\end{array}$ & N & N & Y & Y & Y & Y \\
\hline Wireless scanner & N & N & Y & Y & Y & Y \\
\hline
\end{tabular}

Table 7. Comparing the scanners by application with the features

\begin{tabular}{|c|c|c|c|c|}
\hline $\begin{array}{c}\text { Scanner By } \\
\text { Application/Features }\end{array}$ & Cost & Mobility & Internet Connectivity & Offline Scanning \\
\hline Fixed Scanner & Least & No & Through PC & No \\
\hline Hands-Free & Least & No & Through PC & No \\
\hline Bluetooth Scanner & Medium & Limited & Through PC & No \\
\hline Portable Scanners & Medium & Yes & Through PC & Yes \\
\hline Wireless scanner & High & Yes & Direct & Yes \\
\hline
\end{tabular}

Table 8. Comparing the scanners by technology with the features

\begin{tabular}{|c|c|c|c|c|c|c|}
\hline $\begin{array}{c}\text { Features/ Scanner by } \\
\text { Technology }\end{array}$ & Pen Type & CCD & Laser Scanning & Image Scanning & RFID Scanning & $\begin{array}{c}\text { Object } \\
\text { Recognition }\end{array}$ \\
\hline Weight & Light & Light & Heavy & Heavy & Heavy & Heavy \\
\hline Durability & High & High & Less & Less & Less & Less \\
\hline Scan Distance & Very Close & Very Close & Close & Close & Long & Close \\
\hline
\end{tabular}




\begin{tabular}{|c|c|c|c|c|c|c|}
\hline Bad Object Read & No & No & Yes & Yes & Yes & Yes \\
\hline Barcode Type & 1D & $1 \mathrm{D}$ & $1 \mathrm{D}$ & $1 \mathrm{D} / 2 \mathrm{D}$ & NA & NA \\
\hline Motion Tolerance & No & No & Yes & Yes & Yes & Yes \\
\hline Scan Area & Less & Less & Wide & Wide & Very Large & Wide \\
\hline Cost & Low & Low & Medium & Medium & High & High \\
\hline Mobility & No & No & Yes & Yes & Yes & Yes \\
\hline Local Memory & No & No & Yes & Yes & Yes & Yes \\
\hline
\end{tabular}

\section{FUTURE OF BARCODE SCANNING}

We have seen barcodes printed on nearly every item in grocery store. They are either UPC or EAN linear barcodes. There are about 300 other different types of barcodes, out of which code 39 are the most popular. Also there are 2D barcodes that store a large amount of information in a smaller space than linear barcodes. There are two basic advantages of barcode scanning over manual entry, their speed and accuracy. For the entry of 12 characters of data, keyboard takes $12 \mathrm{sec}$, while scanning of 12 character data takes only $3 \mathrm{sec}$. The error rate for typing is one substitution error for every 300 characters types. Error rate for barcode range from 1 substitution for every 15000 to 36 trillion characters scanned. It is speculation that RFID tags may make the barcodes obsolete, but it is difficult for the tags to take the place of barcode as all RFID tags contain a radio transmitter, as whereas barcodes are made up of inks. The cost involved in RFID is the primary reason for not replacing barcode scanning. RFID is consider as it stores more data than the popular linear or 1D barcode, which stores more numbers and letters in the smallest space is Code 12B.However,2-D barcode will store more data as compare to any linear barcode. The barcode can be prevented from being copied by using a special over laminate that only allows infra red light to pass through. This proves that the future of barcode is quite safe and this will become more popular among people [6, 7].

\section{REFERENCES}

[1] Sun Hong-ying 2009. The Application of Barcode Technology in Logistics and Warehouse Management.
IEEE First International Workshop on Education Technology and Computer Science.

[2] Felix von Reischach, Stephan Karpischek, Florian Michahelles, Robert Adelmann 2010. Evaluation of 1D barcode scanning on mobile Phones. IEEE Conference on Internet of Things.

[3] Want, R. 2004. Enabling ubiquitous sensing with RFID. IEEE Journal Computer.

[4] Younghwan Yoo, Jinhwan Kim, Haosong Gou, and Yijiang $\mathrm{Hu}$ 2009. RFID Reader and Tag Multi-hop Communication for Port Logistics. IEEE International Symposium on a World of Wireless, Mobile and Multimedia Networks \& Workshops.

[5] Kongqiao Wang, Yanming Zou, and Hao Wang 2005. Bar Code Reading from Images captured by camera phones. 2nd International Conference on Mobile Technology, Applications and Systems.

[6] Juho Vartiainen, Tommi Kallonen, Jouni Ikonen 2008. Barcodes and Mobile Phones as Part of Logistic Chain in Construction Industry. 16th International Conference on Software, Telecommunications and Computer Networks.

[7] Wang Daxi, Wu Liangqi, Wei Zengpei,Zhu Haiwei 2010. Application Research of Monitoring for Logistics Information Based on Intelligent Barcode. International Conforence on Computer Application and System Modeling. 